\title{
El cuerpo trans*: territorio de poder, lugar de resistencia al sistema heteronormativo
}

\section{The trans* body: territory of power, place of resistance to the heteronormative system}

María José Martínez Eraso", Heidi Smith Pulido Varón"

Universidad Católica Luis Amigó

Recibido: 8 de noviembre de 2019-Aceptado: 15 de diciembre de 2020-Publicado: 1 de enero de 2022

Forma de citar este artículo en APA:

Martínez-Eraso, M., \& Pulido-Varón, H. S. (2022). El cuerpo trans*: territorio de poder, lugar de resistencia al sistema heteronormativo. Revista Colombiana de Ciencias Sociales, 13(1), 260-277. https://doi.org/10.21501/22161201.3410

\section{Resumen}

Este artículo reflexiona sobre el cuerpo trans* como territorio de poder que hace resistencia al poder hegemónico, cuyo orden busca "normalizar" los cuerpos de acuerdo con lo estipulado socialmente bajo el "deber ser" del género. Para ello se realiza un abordaje teórico sobre el cuerpo, desde posturas como las de Foucault y Butler que lo conciben como entidad que en sí misma es poder. Con base en los referentes teóricos presentados, se expresan los argumentos que permiten entender los cuerpos trans* como territorios de subversión frente al orden establecido sobre estos. Se concluye que las personas trans, si bien se resisten

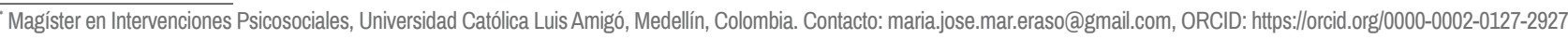
" Magíster en Desarrollo. Docente Investigadora Facultad de Psicología y Ciencias Sociales, Universidad Católica Luis Amigó. Pertenece al grupo de investigación Estudios de Fenómenos Psicosociales, Medellín-Colombia. Contacto: heidi.pulidova@amigo.edu.co. ORCID: https://orcid.org/0000-0001-8198-0896
} 
a la heterosexualidad obligatoria, posiblemente no sea de forma estructural y radical, sino desde dentro del orden social, generando ciertas fisuras en sus prácticas y performances que presentan ante el sistema, develando una presencia que excede sus linealidades.

\section{Palabras clave}

Cuerpo; Resistencia; Género; Cuerpo trans*; Poder.

\section{Abstract}

This article reflects on the trans* body as a territory of power, which resists the hegemonic power, whose order seeks to "normalize" the bodies according to what is socially stipulated under the "duty to be" of gender. For this, a theoretical approach is made to the body, from positions such as those of Foucault and Butler that conceive it as an entity that in itself is (is) power. Based on the theoretical references presented, the arguments that allow us to understand trans* bodies as territories of subversion against the order established on them are expressed. It is concluded that trans people, although they resist compulsory heterosexuality, may not be structurally and radically, but from within the social order, generating certain fissures in their practices and performances that they present to the system, revealing a presence that exceeds their linearities.

\section{Keywords}

Body; Endurance; Gender; Trans* body; Power. 


\section{Introducción}

La conceptualización del cuerpo no está exclusivamente relacionada con lo biológico, o lo entendido como "natural", por el contrario, implica atenderlo como un territorio construido, tensionado y apropiado desde procesos de subjetivación y poder. En palabras de Barrera-Sánchez (2011), el cuerpo es un texto donde se asientan las relaciones sociales de producción y dominación, por tanto, supone un carácter socio-histórico que permite comprender la historia de dominación que se ha ejercido hacia este. En una línea similar, Preciado (2002) lo asume como una construcción, "un archivo orgánico de la historia de la humanidad como historia de la producción-reproducción sexual, en la que ciertos códigos se naturalizan, otros quedan elípticos y otros son sistemáticamente eliminados o tachados" (p. 23).

En este sentido, el cuerpo revela tramas de poder que se tensionan, dinamizan y superponen permanentemente, proyectándolo como el primer territorio donde tienen cabida los deseos y desencuentros del ser humano con la cultura. Esto nos habla de una construcción social que condensa vertientes políticas y revela las múltiples marcas de los afectos, del tiempo y la relación con los códigos de una época, es decir de ejercicios de poder y resistencia ante aquello que se le permite hacer-evocar.

Martínez (2014) postula que el cuerpo, al estar permeado por los patrones culturales tan marcados, expresa la presión social que se le impone, reflejando el momento social al que pertenece, actuando y presentándose según el orden imperante. Esta obediencia no se sujeta exclusivamente a imposiciones coercitivas, sino al influjo de sumisión voluntaria que provoca el disciplinamiento.

La concepción del cuerpo como lugar donde se pueden materializar y comprender las relaciones de poder emerge en la ambición de las disciplinas modernas con el objetivo de "incrementar la utilidad del cuerpo y aumentar su fuerza" (Martínez, 2014, p. 133), lo que resulta acorde con las demandas de productividad y sus requerimientos de cuerpos "normales", dóciles y obedientes a las exigencias del sistema. Según Le Breton (2002), el cuerpo en la modernidad, "se alinea con las otras máquinas de la producción, sin beneficiarse con una particular indulgencia” (p. 80), por lo que surge el interés de su comprensión y disciplinamiento para ejercer control y dominio sobre el mismo.

Por ello, Foucault (1992) refiere que el cuerpo humano existe en y a través de un sistema político, dado que el poder provee cierto espacio determinado al individuo, un espacio donde se estipulan comportamientos y posturas específicas según el orden social impuesto. Así, se entiende el cuerpo como un territorio que ha sido dominado por sociedades disciplinarias, a través de mecanismos punitivos para que obedezca al orden hegemónico y mantenga el temor de quebrantar 
lo impuesto. Vale aclarar que el concepto de disciplina se deriva de la necesidad de impedir que el deseo emerja, por ello se limita a la experimentación y se promueve el sometimiento voluntario (Useche, 2016).

En el caso particular de los cuerpos trans*, los discursos que históricamente han intentado controlarlos son el médico-legal y el religioso. En el área de la medicina, durante varios años se nombró a la transexualidad como una enfermedad y se la contempló como un trastorno de identidad de género en la clasificación internacional de enfermedades (CIE) y en el Manual Diagnóstico y Estadístico de los Trastornos Mentales (DSM), lo que conllevó etiquetar lo trans como una categoría "anormal" que se requería controlar y curar. Actualmente, en la última versión DSM $\mathrm{V}$, aparece el término disforia de género, eufemismo de la palabra trastorno, que no logra abolir la patologización de comportamientos sexuales no hegemónicos, por cuanto sostiene la idea de señalar la desviación de lo considerado normal por el poder experto y científico de la medicina (Campo \& Herazo, 2018).

En cuanto al orden religioso, Soley (2014) expresa que existe un orden moral y religioso tradicional, que no aprueba la transexualidad por considerarla como una conducta inapropiada ya que busca cambiar el orden natural, que puede o no disponer el cuerpo de acuerdo con los deseos humanos. La religión señaló los cuerpos trans* son como contra naturales, pues estas personas transgreden la naturaleza humana definida $y$, por tanto, suponen que sean intervenidos o vigilados.

Así, mediante los discursos de dominación, se ha provocado que los cuerpos transgénero y transexual queden desterrados de lo humano al no responder al orden binario que busca aniquilar las disidencias de género (Butler, 2006). Aquí conviene señalar que el presente artículo utiliza el prefijo trans* planteado por Platero (2014), como un "concepto paraguas" que permite desdibujar la dicotomía del género y acoger las diferentes disidencias, incluyendo identidades del género fluido. El símbolo del asterisco, señalado por el mismo autor, significa que no hay una sola forma de lo trans, que la lógica homogeneizante no tiene lugar.

La fuerza y el dominio de los discursos hegemónicos actúan en las dimensiones microsociales sosteniendo estigmas y prejuicios y, con ello, diversidad de violencias hacia las personas que interpelan la cisheteronormatividad. La presión social ejercida hacia hombres y mujeres que hicieron tránsito de género revela profundos riesgos psicosociales expresados individual y colectivamente a lo largo del ciclo vital. Carvajal (2018) refiere que la transfobia puede causar sufrimiento, violación de derechos, dolor, malestar y, en los casos extremos, incremento de la conducta suicida, como resultado del sentimiento de inadecuación social, rechazo y violencias persistentes. 
Según Le Breton (2002), la "mirada es figura hegemónica de la vida social" (p. 102), de modo que las personas que decidieron hacer el tránsito de género deben sobrellevar cotidianamente miradas violentas de discriminación y rechazo, al presentarse a una sociedad que no acepta lo distinto e impone una lógica de normalidad que acepta a quienes acogen los parámetros de las dinámicas sociales de productividad, y elimina, excluye o intenta normalizar a quienes no lo hacen.

El cuerpo trans* significa recinto donde el poder hegemónico del género ejerce sus represalias, pero también, al presentarse al mundo, se traducen en territorios que reflejan las fisuras al sistema heterosexual, emergiendo como cuerpos deseantes, que direccionan resistencias pese a las implicaciones que esto conlleva. Al entender el cuerpo con capacidad de interpelar aquello que le imponen y reconocerlo como morada que se apropia, habita, transita y transforma con la presencia, se le dota de un poder que puede hacer resistencia, al aparecer y presentar nuevas espacialidades en medio de ambientes donde ejercen control discursos hegemónicos de dominación.

En este sentido, el cuerpo no se entiende exclusivamente como pasivo, víctima de dominaciones, sino como entidad que también evoca rebeldía, desobediencia, un lugar que tiene voz y capacidad de generar quebrantos en el sistema, reafirmando la postura de Foucault (1992), según la cual, en relaciones de poder-dominación se despliegan ejercicios de resistencia. En coherencia, el cuerpo es un espacio donde ocurren negociaciones sociales y políticas entre las personas, y en este sentido se constituye como un territorio micropolítico, atendiendo a que:

\section{La micropolítica se constituye en una estrategia de resistencia al poder, no necesariamente pensada en términos violentos sino como contraposición de la vida política en el sentido más amplio del término y desde la "lucha en lo micro", desde lo local y la vida cotidiana. (Vargas, 2010, p. 20)}

Por consiguiente, los cuerpos trans* pueden considerarse como territorios que ejercen resistencia desde lo micropolítico, lo cual se ve reflejado en su cotidianidad y en su diario vivir. Estas disidencias sexuales imponen nuevos códigos, lenguajes y estéticas desde un cuerpo deseante que busca aparecer en el mundo de forma usual, ser visualizado y reconocido, rompiendo o jugando sutilmente con las estructuras sociales impuestas.

Es importante señalar que el poder, desde la perspectiva de Foucault, se concibe disperso por la estructura social y es utilizado para ejercer dominio, pero también como posibilitador de lugares de resistencia. Así, para Foucault (1976), la condición humana esta inevitablemente sujeta al poder y su eficiencia; sin embargo, esta situación expresa diversas tensiones entre sus objetivos disciplinarios, que buscan normalizar las conductas humanas, y las posturas que se resisten frente a las regulaciones, abogando por cuerpos que pueden aparecer de forma deseante, rebeldes, distinta a los estereotipos binarios. Esto último, como ya se ha mencionado, al concretarse dentro de un marco de un sistema social puede asumir una opción disponible también sujeta a una dinámica de control, dominio y mercantilización. 
Contemplando lo anterior, el objetivo del presente artículo es reflexionar sobre el cuerpo trans* como territorio de poder que hace resistencia al poder hegemónico, cuyo orden busca "normalizar" los cuerpos de acuerdo con lo estipulado socialmente bajo el "deber ser" del género. Para ello, primero se presentan posturas que permiten entender el cuerpo como territorio de poder, para posteriormente centrarse exclusivamente en el cuerpo trans*. En este sentido, se abordan principalmente los pilares conceptuales de Michel Foucault y Judith Butler, al ser autores que han estudiado el poder hegemónico que se ha ejercicio sobre los cuerpos que no incorporan en su performance el orden establecido con respecto al sexo, género y deseo sexual, y así han presentado comprensiones frente a los ejercicios de resistencia que realizan estos cuerpos, que exceden la norma e interpelan lo que se ha determinado como irrompible.

\section{El cuerpo como territorio de poder}

"Cuando el poder no puede expresarse a través de la ley y del código, utiliza los cuerpos como territorio de inscripción” (Segato, 2016, p. 178).

Según Nates (2010), el territorio se define a partir de significaciones culturales, como un "escenario de poder, de gestión y de dominio" (p. 211), donde se materializan prácticas sociales de diferente índole y se manifiestan intereses que evocan las relaciones de poder que se ejercen en él. La misma autora menciona que el territorio, como construcción cultural, es susceptible de transformaciones de acuerdo con momentos sociohistóricos particulares. Así, en el territorio se pueden conocer las relaciones de poder, porque más que un espacio físico refleja interacción, tensiones e implica intersubjetividad.

En congruencia, al comprender el cuerpo como territorio, su definición va más allá de concepciones biologicistas o esencialistas y se centra en las relaciones de poder que lo nombran y definen. Vásquez y Carrasco (2017) sitúan el cuerpo como un espacio en el cual los discursos de poder se instituyen e intentan sostenerse.

A través del cuerpo se entiende la organización social y sus cambios socio-históricos. Tal como lo expresa Foucault (1992), "en el cuerpo se puede conocer los regímenes de poder a través de las diferentes tecnologías de castigo utilizadas para disciplinar" (p. 24). Así, se puede reconocer como foco de imposiciones sociales, control y dominación que de no ser asumidas derivan un repertorio de sanciones justificadas y naturalizadas por la hegemonía normativa.

Cabe señalar que el disciplinamiento que se hace a los cuerpos se despliega en lo micro, permea el diario vivir, y atraviesa todo el cuerpo social. Según Piña (2004), la sociedad que busca disciplinar los cuerpos utiliza diferentes mecanismos que se extienden en prácticas de la vida cotidiana, en costumbres, hábitos y otras acciones que cosifican y mercantilizan el cuerpo en el 
marco de un sistema económico. En este sentido, Foucault (1992) considera que la vigilancia y control sobre el cuerpo de las personas tiene un carácter biopolítico, es decir, conecta dimensiones políticas y de poder a la vida rompiendo con la idea de un poder exclusivamente localizado en el Estado y en los macro poderes:

\section{El poder no está localizado en el aparato de Estado, y nada cambiará en la sociedad si no se transforman los mecanis- mos de poder que funcionan fuera de los aparatos del Estado, por debajo de ellos, a su lado, de una manera mucho más minuciosa, cotidiana. Si se consiguen modificar estas relaciones o hacer intolerables los efectos de poder que en ellas se propagan, se dificultará enormemente el funcionamiento de los aparatos de Estado. (Foucault, 1992, p. 108)}

En este sentido, el poder no se establece y legitima exclusivamente en las jerarquías sociales y con mecanismos de fuerza o violencia directa, sino que pasa por el sujeto mismo y sus relaciones, es decir, se refleja en las interacciones con el otro, en sus versiones de sí y del mundo, por ello su ejercicio puede dar lugar a dominaciones sutiles, casi imperceptibles. Para Foucault (1976), desde la anatomopolítica se busca educar y corregir los cuerpos para lograr un sometimiento y docilidad, y con ello maximizar la productividad. Es decir, el cuerpo se somete a un proceso de domesticación, evitando que exprese sus deseos y atente contra el orden impuesto. Con relación a ello, Escobar (2015) plantea que:

El poder se sirve de técnicas y dispositivos de vigilancia y control que vuelven al cuerpo completamente dócil y al mismo tiempo completamente eficiente para la realización de su función en el engranaje. El propósito es disciplinarlo para aumentar su eficiencia mediante su obediencia. (p. 149)

Según lo mencionado hasta el momento, lo que buscan los poderes hegemónicos es crear cuerpos obedientes, dóciles, disciplinados para que asuman las normas impuestas en su cotidianidad, y se genere una obediencia voluntaria, suponiendo una presunta deliberación. Esto sucede, según Foucault (1976), porque existe una mirada normalizadora que establece lo correcto y lo incorrecto, lo que se puede permitir o no, aquello que por realizarlo puede tener como consecuencia el castigo. Dada esta mirada, los cuerpos actúan con el propósito encajar en lo "normal", estipulado en un juego de poderes que buscan ejercer control sobre los cuerpos, y evitan entrar en el campo de lo "anormal", porque esto significa expulsión y destierro de lo considerado como humano.

Así, el control sobre los cuerpos contiene tanta fuerza que no requiere una mirada vigiladora, panóptica, que evoque lo permitido o lo que no es. Por el contrario, las personas han incorporado en sus repertorios de respuesta sociales, códigos del orden disciplinario que al ser desplegados sostienen las dinámicas de poderes hegemónicos, aunque esto no exime la presencia de la resistencia y los recursos de interpelación.

Dado lo anterior, se puede comprender cómo ante la linealidad y mecanicidad que se le impone al cuerpo, se hallen movimientos que responden desbordando los límites impuestos, enunciando excesos, deseo y exhibiendo su capacidad de resistencia y transformación. Para Butler (2002), 
el cuerpo es un espacio en el que el poder se materializa, en este sentido no se comprende como un sitio vacío, pre discursivo, como en la lógica biomédica, sino que refleja una construccióndeconstrucción permanente que se juega por y en las relaciones de poder.

En coherencia, el cuerpo puede concebirse como un territorio en permanente tensión y disputa, donde "lo simbólico, lo imaginario y lo melancólico se materializan en una realidad" (García, 2010a, p. 380), un campo de batalla, no determinado e inacabado, algo a construir, algo a tomar, un lugar en el que el poder constantemente se permea. Por ende, al considerarse el cuerpo como un territorio de poder se exceden visiones que lo sitúan en un lugar de pasividad frente a la opresión, y en cambio se connota la capacidad de subvertir eso que le imponen:

\section{El cuerpo es también la ocasión para la insurrección, entendiendo que ésta no se ejerce desde una entidad pura que se opone al poder sino desde una entidad que es poder. Es decir, el cuerpo es el mecanismo mediante el cual el poder extiende sus tentáculos y es, a su vez, la ocasión para revertir este poder y materializarlo en posibilidades insospechadas. (García, 2010a, p. 381)}

Atender el cuerpo como entidad que en sí misma es poder, permite darle un lugar protagónico dentro de los procesos de resistencia desplegados en lo microsocial para hacer frente a aquellos discursos y prácticas excluyentes, disciplinarias y normalizadoras. Así, la resistencia se entiende, en términos de González et al. (2011), como la dispersión de un poder afirmativo traducido en potencia de vida más que de muerte, sin tener la necesidad de ejercer violencia para hacer grietas frente aquel orden social dicotómico, discriminativo, prejuicioso que establece lo normal y lo anormal, las vidas posibles y a aquellas que no son aceptadas en la sociedad como humanas.

Es importante aclarar que el tipo de resistencia ejercidas por los cuerpos frente a aquello que los ha dominado es difícil de percibir, primero porque se expresa en dimensiones cotidianas, microsociales, donde son reducidas, devaluadas e invisibilizadas en las lógicas del dominio hegemónico; segundo, porque se da dentro del sistema social y bajo la condición de "sujeto sujetado", es decir, aunque hacen fisura, coexisten con patrones de orden y control, de los que no pueden desligarse totalmente. Por este motivo es que algunos ejercicios de resistencia noviolentos no se reconocen como tal porque interpelan algunas dinámicas sociales, pero adoptan otras como forma de sobrevivencia en la sociedad.

Algunos de los ejercicios de resistencia noviolentos no son reconocidos al desarrollarse en la cotidianidad, en aquel espacio de construcción en el cual se normaliza lo impuesto y en donde se da paso a la subversión creando realidades alternativas, desde acciones que se resisten a quedar relegadas en la periferia y que insisten políticamente al presentarse e irrumpir en el orden establecido. En este sentido, Scott (2000) entiende las formas de resistencia cotidiana como acciones reiterativas de personas que son oprimidas, que producen un "discurso oculto" desde el cual buscan cuestionar el poder hegemónico de forma indirecta, esto con el fin de proteger su vida e 
integridad. En una vertiente similar, Larracoechea y Portocarrero (2016) refieren que "estas técnicas de resistencia de bajo perfil a menudo no son identificadas por los poderosos y eso ayuda a proteger a los oprimidos de la represión" (p. 21).

Así, a través de acciones sutiles que se desarrollan en la vida cotidiana, se agrieta el sistema hegemónico, aunque no necesariamente se rompe por completo el orden impuesto, e incluso puede que no exista una reflexión consciente de los ejercicios de resistencia que sus prácticas representan, en tanto estas se despliegan y son percibidas como respuestas singulares, emocionales, afectivas frente a sí mismo y el entorno. Con relación a ello Larracoechea y Portocarrero (2016) plantean cuestiones como:

¿es necesario que la resistencia sea reconocida por los otros como tal para que sea resistencia?; $y$ ¿deben los sujetos de la resistencia ser conscientes de que se están resistiendo a ciertas formas de poder para que podamos hablar de resistencia? (p. 21)

Interrogantes que invitan a la reflexión sobre el poder de la vida cotidiana y las formas microsociales construidas por los actores para incidir políticamente sobre un estado de las cosas determinista.

\section{El cuerpo trans* como forma de resistencia al poder heteronormativo}

En el siglo XIX surge la necesidad en el campo de la sexología de diferenciar entre atracción por parte de personas del mismo sexo asignado y transición de género, y es así como a partir de esta diferenciación se acuña la categoría clínica travestismo. Después, aparece el concepto transexual, introducido por el sexólogo David Cauldwell y por Harry Benjamin; en este momento histórico se define la transexualidad como una ruptura entre lo que se tiene y lo que se desea ser, buscando de esta manera los discursos para patologizar (Coll-Planas \& Missé, 2015).

La denominación transexual surge y se introduce desde discursos biomédicos y religiosos, que dispersos en la interacción social han contribuido a configurar prejuicios y estigmas que acrecientan la discriminación y exclusión de estas personas. Al respecto, Furcia (2013) plantea que en el orden médico reconocen desde la patologización a las personas que interpelan las normas de género, de modo que "antes de ser consideradx ciudadanx se debe ser diagnosticadx como enfermx mental" (p. 146). Para ser reconocidos como ciudadanos las personas trans* deben pasar por un largo y tedioso proceso médico-legal para poder gozar de sus derechos y contar con la posibilidad de presentar al mundo los cuerpos deseantes. 
Los cuerpos trans* luchan contra la "cis-hetero-normatividad", la cual impone una supuesta normalidad cuando existe una correspondencia entre los géneros aceptados, en congruencia con los órganos sexuales y la replicación de comportamientos heterosexuales (Cárdenas del Río, 2016). Esta situación se sostiene en la linealidad con que se ha asumido la relación sexo-género.

Al respecto, Butler (2006) postula que el sexo se ha comprendido como un hecho natural, pre discursivo, anterior a la cultura. Sin embargo, la autora lo comprende por efecto del género, es decir, como una construcción cultural que se ha buscado definir desde razones biologicistas, para mantener el discurso dominante de la biología como destino. El género hace referencia a prácticas culturales normativas y performativas, lo cual refleja aspectos sociohistóricos y el poder hegemónico. El género se entiende como performativo por la razón de que se construye por actuaciones, y el lenguaje que se repite constantemente hasta tal punto que logra naturalizarse.

Butler (2002) considera que el sexo es un "ideal regulatorio" (p. 18), y en sí la materialización del mismo; su presunto origen "natural" se obtiene por prácticas impuestas y reguladas socialmente, de manera que tanto el sexo como el género se producen y sostienen a través de discursos de poder. En consecuencia, Butler (2007) sostiene que se ha construido e instaurado un régimen normativo en lo que respecta al género y la sexualidad, un poder heteronormativo, una heterosexualidad obligatoria.

Este tipo de poder define las identidades de género correctas y ejerce castigo sobre aquellas que irrumpen lo estipulado, de hecho, las define como vidas que no merecen ser vividas; en palabras de Butler (2010), vidas que se han designado "merecedoras de ser lloradas" (p. 64), y otras que no, a razón de que para algunas personas, al ser ininteligibles, no son consideradas como vidas en realidad. En efecto, Butler (2007) afirma la existencia de géneros ininteligibles e inteligibles, estos últimos son los que, de alguna manera, instauran y mantienen relaciones de coherencia y continuidad entre sexo, género, práctica sexual y deseo" (Butler, 2007, p. 73). Se evidencia, así, al poder como un elemento fundamental que atraviesa la visión lineal de la sexualidad, constituyendo una matriz cultural heterosexual en la que se “exige que algunos tipos de 'identidades' no puedan 'existir', aquellas en las que el género no es consecuencia del sexo y otras en las que las prácticas del deseo no son 'consecuencia' ni del sexo ni del género” (Butler, 2007, p. 72).

El poder heteronormativo se guía a través de la matriz de correspondencia entre sexo, género y deseo sexual, y las personas que no se ajustan a dicho orden reciben un sinfín de violencias, naturalizadas y legitimadas, que van dirigidas hacia el cuerpo. Para Butler (2002) esto indica que el cuerpo se ha convertido en un instrumento de control político, estipulado sexualmente desde el nacimiento, modificable e influenciable cotidianamente mediante estándares, normas rígidas de género, orientados a que los cuerpos cumplan con los estereotipos opresores de una idealidad cor- 
pórea femenina y masculina (Lozano, 2017). Los estereotipos de género buscan instaurar el orden binario cerrando las posibilidades de salirse de él, y es precisamente lo que el cuerpo trans*, al reelaborarse desde el deseo, excede y transgrede.

De acuerdo con lo anterior, existen algunos límites dentro del campo de la matriz de inteligibilidad, y es ahí donde otras matrices subversivas pueden relevarse, develarse. En este proceso de aparición se deconstruye el género y el sexo como tal, al considerarse estos dos como construcciones socioculturales. Al respecto, Butler (2006) refiere: "El cuerpo es aquello que puede ocupar la norma en una miríada de formas, que pueden exceder la norma, volver a dibujar la norma y exponer la posibilidad de la transformación de realidades a las cuales creíamos estar confinados" (p. 307). Esto evoca de nuevo el concepto del cuerpo como territorio, pues se comprende como un espacio que puede transformarse y transformar realidades al exceder las fronteras que se creen inalterables, demostrando que es posible proponer mundos diferentes en medio de las limitaciones construidas por la sociedad.

En este sentido, el cuerpo trans* no se define exclusivamente como receptor de imposiciones sociales, sino que también puede subvertir el orden social, al no cumplir con ciertas normas de género, al cuestionar el binarismo y, en sí, al armar su cuerpo en variedad enfrenta lo que se le estipula. Al respecto, Lugo (2013) menciona que ante las coacciones de la heteronormatividad se configuran cuerpos como artefactos transgresores que resisten la ambición hegemónica de las disposiciones socio-culturales.

Los cuerpos trans*, quienes se resisten a dichos parámetros, irrumpen la matriz de heteronormatividad y se presentan al mundo con un cuerpo deseante. El deseo que expresa ese cuerpo se mantiene en una tensión con el poder y por ello desafía la norma de género. Al presentarse al mundo estos cuerpos disidentes se evidencia la expresión de deseos, y por este hecho se consideran cuerpos transgresores. A pesar de conocer las implicaciones que trae consigo el tránsito en esta sociedad, se hacen visibles, buscan ser escuchados y reconocidos desde su humanidad (Prieto, 2017).

En este sentido, se comprende que el cuerpo trans se resiste al orden heteronormativo, entendiendo la resistencia como una respuesta al orden de dominación impuesto, buscando alternativas creativas para enfrentar al poder dominante que controla y no permite la expresión del cuerpo deseante. Es así que, mientras el poder anatomopolítico buscar dominar el cuerpo, y a través de él su subjetividad, la resistencia nace como un espacio de fuga donde la persona busca afirmarse (Lugo, 2013).

Los cuerpos trans* y sus narraciones revelan identidades que se han de-construido en los bordes del sistema sexo-género, presentando formas políticas, subjetivas, creativas e incómodas, que señalan micropoderes encarnados en un cuerpo, asumido como instrumento para defender 
su derecho al autorreconocimiento. La resistencia que ejercen estos cuerpos trans* no implica, necesariamente, un desarrollo formal de procesos de empoderamiento, ni radicalismos o rupturas abruptas con el sistema macrosocial, sino que habla de lugares subjetivos, íntimos y vivenciales, que interpelan los patrones establecidos y optan por movimientos contradictorios que van generando fisuras microsociales donde también circula el poder hegemónico. Estas personas, al hacerse visibles en el campo social, transgreden aquello que se ha catalogado como "natural", cuestionando aquellas ideas esencialistas que se han sostenido a lo largo de tiempo.

Escobar (2013) sugiere la existencia de dos formas de resistencia que han adoptado las personas trans, una es la queer y otra es lo barroco. La primera está orientada a hacer visible lo anormal y propone una cierta utopía al buscar un cambio radical de ese orden dicotómico (mujer-hombre) y de la linealidad que se ha establecido de sexo, género y deseo sexual. Por su parte, lo barroco se considera una manera de resistir, pero dentro del orden, no propone hacer una ruptura estructural sino que pretende abrir nuevas posibilidades de existencia a eso que a la normalidad le resulta bizarro, es decir, se enfrenta al poder heteronormativo pero se mantienen dentro del sistema mismo, expresando corporalidades que si bien se pueden acomodar al orden vigente, perturban a una sociedad que se ve normalizada por un discurso homogeneizador de género.

Por tanto, el tipo de resistencia barroco se relaciona con lo que postula Vargas (2010) acerca de un tipo de resistencia que busca generar grietas en el orden hegemónico, pero de forma irregular, individual y microespacial. Las personas trans* se resisten al poder heteronormativo en medio del ambiente coercitivo, prejuicioso, por tanto, sus acciones de resistencia muchas veces son de sobrevivencia, actos cotidianos de afrontamiento, ejercicios de interpelación del sistema en el diario vivir, que, por ser locales, microsociales, no pierden su fuerza y trastocan la heteronormatividad.

Nieto (2013) afirma que "la resistencia es solo potencia y no acto, por que ciertas situaciones de poder y dominación no desencadenan, necesariamente, actos y prácticas de resistencia, sino muchas veces prácticas de obediencia voluntaria" (p. 47). Es importante señalar que la resistencia ejercida por los cuerpos trans* se da desde la sobrevivencia, porque aparecer dentro de un sistema violento, discriminador con la otredad, vulnera su propio derecho a existir y autoreconocerse. En estos términos, algunas corporalidades no normativas pueden adoptar estándares sociales, desde la dicotomía femenino-masculino, sin que ello signifique que se ha eliminado su carácter de resistencia.

Es así como García (2010b) refiere acerca del tránsito femenino: "los tacones, las siliconas, las hormonas que usamos pese a que reproducen estereotipos de lo femenino pueden convertirse en elementos de rebeldía y liberación" (p. 5), es decir, estrategias políticas, cuerpos politizados que reclaman derecho a enunciarse y construirse desde sus deseos y necesidades. 


\section{Consideraciones finales}

Teniendo en cuenta lo expuesto a lo largo de este documento, es posible asumir el cuerpo más allá de sus bordes biológicos. Entenderlo como territorio de poder expresa sus múltiples posibilidades de presentarse y permite comprender las marcas de las relaciones sociales y sus aspectos sociohistóricos, casi siempre evidenciando crudas luchas y tensiones entre las disposiciones culturales, los discursos expertos y el deseo.

Con el advenimiento de la racionalidad moderna y, anudada a esta, el disciplinamiento del cuerpo provocó que los cuerpos se sometieran a procesos de domesticación que facilitara los anhelos de productividad y el sostenimiento del orden social dominante. Aun cuando el proyecto moderno evidenció sus fisuras y se resquebrajó, persiste la idea de sus instituciones de concebir el cuerpo en el mismo ideal, favoreciendo que el régimen disciplinar se incorpore, sea naturalizado y evocado por el mismo sujeto, sin la necesidad de figuras de vigilancia y control permanente, lo que garantiza la persistencia de los códigos del deber ser; esto significa que los discursos de poder son legitimados y automatizados en cada uno de los actos y experiencias de la vida cotidiana. Es relevante referir que esto es posible gracias a la dispersión del poder en todo el sistema social, en toda la trama de las relaciones que atraviesan al sujeto desde momentos tempranos, por tanto, puede desplegarse de forma imperceptible en asuntos rutinarios de la vida cotidiana relacionados, por ejemplo, con estéticas corporales o prácticas sexuales abiertas, que vistos superficialmente no se perciben como ejercicios de poder, pero que en su raíz revelan el potencial de libertad y emancipación.

Lo anterior revela una dimensión política que tiene lugar más allá de referencias formales del poder, de procesos macrosociales, de demandas y movimientos frente a la estructura social, y en cambio presenta un abanico de opciones que en su singularidad y sutileza se mueven en lugares microsociales produciendo movimientos y contradicciones.

En este sentido, el cuerpo emerge como territorio político donde se han perpetuado diferentes relaciones de dominación y, con ello, foco de violencias y agresiones al no actuar según lo establecido por el poder hegemónico que busca dominarlo y disciplinarlo, pero también expresa un sentido político vívido, de oposición y lucha por el autorreconocimiento y el deseo.

Este escrito ha insistido en que el poder heteronormativo, justificado en la correspondencia entre sexo, género y deseo sexual, considera a los cuerpos trans* abyectos y, como tal, los excluye y aniquila. Desde ahí se presentan miradas totalizadoras que incluyen aquellas identidades que se ajustan al sistema de género y excluyen a las vidas que interpelan el orden instaurado por creer que son extrañas, diferentes, "anormales" y, por tanto, deben ser expulsadas; de esta manera, establecen quiénes son vidas posibles, es decir, qué identidades son inteligibles y cuáles no. 
El cuerpo trans* ha tenido que sobrevivir ante esas voces que persisten en la sociedad y reproducen el orden de la heteronormatividad. Esta población, al ser marcada con un estigma social, es ubicada en la "anormalidad" y, por lo tanto, en la "exclusión”, y desde ahí tienen que afrontar de forma cotidiana las violencias excesivas ejercidas en círculos filiales y afectivos cercanos, como también por actores sociales, como el Estado y sus instituciones, atravesados por discursos reduccionistas y deterministas como el heteronormativo y el patriarcal que, por ejemplo, mantienen lógicas de impunidad en el sistema jurídico ante los excesos de violencia y estigma que recaen sobre las personas trans*. Esto conlleva que estas personas se sientan sin protección y en riesgo permanente (Colombia Diversa, Fundación Grupo de Acción y Apoyo a Personas Trans (GAAT) y Diversas Incorrectas, 2018). En la misma línea, Caribe Afirmativo y Colombia Diversa (2018) refieren que la violencia de género es estructural, atraviesa diferentes áreas de la vida de un ser humano, se vivencia tanto en lo privado como en lo público, justificado y legitimado a través del prejuicio social hacia estas personas.

A partir de lo anterior, es posible identificar que en la trayectoria vital de las personas trans aparece marcada una violencia intrafamiliar, como también una vulneración de derechos tanto en el sistema legal, educativo y de la salud, de modo que el estigma generado opera en diferentes dimensiones de la vida de estas personas, desde lo íntimo hasta asuntos laborales, educativos y disfrute del espacio público, situaciones que repercuten negativamente en su bienestar integral.

No obstante, estos cuerpos, al visibilizarse, dan a conocer que tienen voz y poder. En este sentido, las personas trans* no solo son receptores de imposiciones sociales y víctimas, como tal, de las miradas calificadoras de normalidad, sino que también pueden oponerse a dicho orden social al irrumpir normas de género, al cuestionar ideas esencialistas y al proponer nuevas posibilidades de existencia a partir del cuerpo deseante, un cuerpo desobediente frente a lo que espera la sociedad, un cuerpo en constante construcción.

De esta manera se puede concluir que los cuerpos trans* se resisten al poder heteronormativo, aunque posiblemente no de forma estructural y radical, sino desde adentro del orden social, generando ciertas fisuras dentro del sistema. Es por ello por lo que la resistencia es entendida como aquella que ofrece herramientas creativas para enfrentar a la hegemonía, interpelando lo establecido, aunque muchas veces de forma sutil y bizarra. En sintonía con esto, se entiende que estos cuerpos al resistirse dentro del género ejercen acciones de resistencia en los bordes, confrontando cotidianamente el sistema, en nombre de la reivindicación de derechos, la dignidad y la diferencia. Así, al comprender el cuerpo trans* como una entidad que en sí misma es poder, y por ello puede interpelar lo impuesto, se logra cambiar de perspectiva y no ubicar a las personas exclusivamente en el papel de sobrevivientes y víctimas de los prejuicios y la discriminación (lo cual también es importante conocerlo), sino más bien como personas creadoras de nuevos espacios de subversión, de resistencia en medio de la subvaloración. Igualmente, obliga a reco- 
nocer ejercicios políticos subjetivos que tienen un impacto microsocial y hacen del cuerpo un instrumento de defensa y reivindicación de la otredad, un ejercicio transformador de los rígidos patrones socioculturales heteronormativos.

Finalmente, el abordaje del cuerpo trans* en clave política y microsocial revela el largo camino y los complejos retos que se sitúan para vencer las barreras construidas frente a la diversidad y la otredad. Esta aproximación sugiere más interrogantes que respuestas, que tendrán que ser abordados para avanzar en la comprensión de las experiencias de las personas trans*. Por ejemplo, es necesario pensar si ¿el cuerpo como resistencia se puede entender así, con otras identidades diversas como la intersexualidad?, ¿cómo deben ser reconocidas las personas que irrumpen el orden heteronormativo?, ¿qué se hace para visibilizar los ejercicios de resistencia cotidianos, sutiles, microsociales?

\section{Conflicto de intereses}

Las autoras declaran la inexistencia de conflicto de interés con institución o asociación comercial de cualquier índole.

\section{Referencias}

Barrera-Sánchez, O. (2011). El cuerpo en Marx, Bourdieu y Foucault. Revista de Ciencias Sociales de la Universidad Iberoamericana, 6(11), 121-137. https://bit.ly/3HYDUat

Butler, J. (2002). Los cuerpos que importan. En A. Amando y N. Domínguez (Dir.), Cuerpos que importan. Sobre los límites materiales y discursivos del sexo (pp. 53-94). Paidós.

Butler, J. (2006). El género en disputa y la cuestión de la supervivencia. En P. Soley-Beltrán (Trad.), Deshacer el género (pp. 293-310). Paidós.

Butler, J. (2007). El género en disputa, el feminismo y la subversión de la identidad. Paidós.

Butler, J. (2010). Capacidad de supervivencia, vulnerabilidad, afecto. En Marcos de vida, las vidas lloradas (págs. 64-80). Paidós 
Campo, A., \& Herazo, E. (2018). Innovations, Reviews and Proposals on the DSM-5: The Case of Sexual Dysfunctions, Gender Dysphoria and Paraphilic Disorders. Revista Colombiana de Psiquiatría, 47(1), 56-64. https://doi.org/10.1016/j.rcpeng.2017.12.008

Cárdenas del Río, M. (2016). La transgresión de la norma de género: experiencias de las identidades "trans" con los servicios de salud (Tesis de pregrado, Universidad de Girona). https://dugi-doc.udg.edu/bitstream/handle/10256/14894/c\%C3\%A1rdenas_del\%20rio. pdf? sequence $=1 \&$ is Allowed $=y$

Caribe afirmativo y Colombia diversa. (2018). La discriminación, una guerra que no termina. http:/colombiadiversa.org/publicaciones/la-discriminacion-una-guerra-no-termina/

Carvajal, A. (2018). Transexualidad y transfobia en el sistema educativo. Revista de la Escuela de Estudios Generales, 8(1), 137-181. http://dx.doi.org/10.15517/h.v8i1.31467

Coll-Planas, G. y Misee, M. (2015). La identidad en disputa. Conflictos alrededor de la construcción de la transexualidad. Papers, 100(1), 35-52. http://dx.doi.org/10.5565/rev/papers.637

Colombia diversa, Fundación Grupo de Acción \& Apoyo a Personas Trans (GAAT) y Diversas incorrectas. (2018). Situaciones de mujeres lesbianas, bisexuales y personas trans en Colombia. Informe sombra para el Comité de la CEDAW. https://colombiadiversa.org/colombiadiversa2016/wpcontent/uploads/2019/02/CEDAW-reporte-espa\%C3\%B1ol-LBTColombia-1.pdf

Escobar, J. (2013). La politización del cuerpo: subjetividades trans en resistencia. Nómadas, (38), 133-149. http://nomadas.ucentral.edu.co/nomadas/pdf/nomadas_38/38_8E_Lapolitizaciondelcuerpo.pdf

Escobar, J. (2015). El cuerpo como artefacto: tecnologías médicas, anatomopolítica y resistencia. Ciencias Sociales y Educación, 4(7), 145-157. https://revistas.udem.edu.co/index.php/ Ciencias_Sociales/article/view/1568

Foucault, M. (1976). Vigilar y castigar. Nacimiento de la prisión. Siglo XXI Editores. (Obra original publicada en 1975).

Foucault, M. (1992). Las relaciones de poder penetran en los cuerpos. En Microfísica del poder. Las ediciones de la piqueta.

Furcia, A. (2013). El género desordenado: Críticas en torno a la patologización de la transexualidad, Miquel Missé y Gerard Coll-Planas. La manzana de la discordia, 8(2), 143-147. https://doi.org/10.25100/lamanzanadeladiscordia.v8i2.1545 
García, J. (2010a). Cuerpos impuros: Butler, Haraway, Preciado. Temita. Revista de Filosofía (46), 377-384. http://institucional.us.es/revistas/themata/46/art_33.pdf

García, A. (2010 b). Tacones, siliconas, hormonas. Teoría feminista y experiencias trans en Bogotá (Tesis de maestría, Universidad Nacional de Colombia). Repositorio Universidad Nacional. https://repositorio.unal.edu.co/handle/unal/6773

González, S., Colmenares, J., \& Ramírez, V. (2011). La resistencia social: una resistencia para la paz. Hallazgos, 8(15), 237-254. https:/www.redalyc.org/pdf/4138/413835204013.pdf

Le Breton. (2002). Antropología del cuerpo y modernidad. Nueva Visión.

Lozano, J. (2017). Prácticas de autocuidado y apoyo en mujeres transgénero durante sus procesos de transformación (Tesis de maestría). Universidad Nacional de Colombia. https://repositorio.unal.edu.co/bitstream/handle/unal/60837/53039976.2017.pdf. pdf? isAllowed $=\mathrm{y} \&$ sequence $=1$

Lugo, S. (2013). Cuerpo-artefacto: aportes de las perspectivas de género y queer a la deconstrucción de los cuerpos «naturalizados. Revista Trilogía, (9), 37-46. https:/dialnet.unirioja.es/ servlet/articulo?codigo $=4521397$

Martínez, A. (2014). La construcción social del cuerpo en las sociedades contemporáneas. Papers, (73), 127-152. https://core.ac.uk/download/pdf/13266976.pdf

Nates, B. (2010). Soportes teóricos y etnográficos sobre conceptos de territorio. Revista Coherencia, 8(14), 209-229. http://www.scielo.org.co/pdf/cohe/v8n14/v8n14a09.pdf

Nieto, J. (2013). La resistencia civil no armada, la voz y la fuga de las comunidades urbanas. Hombre Nuevo Editores.

Piña, C. (2004). El cuerpo un campo de batalla. Tecnologías de sometimiento y resistencia en el cuerpo modificado. El Cotidiano, 20(126). https://www.redalyc.org/articulo. oa? $\mathrm{id}=32512621$

Platero, L. (2014). Trans*exualidades: acompañamiento, factores de salud y recursos educativos. Ediciones Bellaterra

Portocarrero, A., \& Larracoechea, E. (2016). Introducción. En las resistencias nuestras de cada día. Subversiones cotidianas a las violencias simbólicas y materiales. UCA Publicaciones.

Preciado, B. (2002). Manifiesto contra-sexual. Editorial Opera Prima. 
Prieto, S. (2017). Reflexiones sobre el género, el cuerpo y el poder. Cinco voces trans en dialogo con Judith Butler. Universidad Nacional de Colombia.

Rodríguez, T. (2016). Cuerpos en resistencia: experiencias trans en ciudad de México y Bogotá. Nómadas, 44, 273-275. http://dx.doi.org/10.30578/nomadas.n44a16

Sandoval, M. (2017). Comprensión y aceptación de la diversidad y las minorías: único camino hacia la paz. Innovación y Ciencia, 24(1), 91-99. https://innovacionyciencia.com/revistas_pdf/2017-1.pdf

Scott, J. (2000). Detrás de la historia oficial. En Los dominados y el arte de la resistencia. Ediciones Era, S. A de C. V.

Segato, R. (2016). La nueva elocuencia del poder. Una conversación con Rita Laura Segato. En La guerra contra las mujeres. Traficantes de Sueños.

Soley, P. (2014). Transexualidad y transgénero: una perspectiva bioética. Revista de Bioética y Derecho, (30), 21-39. http://dx.doi.org/10.4321/S1886-58872014000100003

Useche, O. (2016). Potencia, cuerpo y resistencia. Iztapalapa. Revista de Ciencias Sociales y Humanidades, 82(38), 75-100. https://doi.org/10.28928/revistaiztapalapa/822017/atc3/ usechealdanao

Vargas, R. (2010). Del tumbao al trapiao: negociaciones corpoterritoriales de las mujeres negras en el servicio doméstico de la ciudad de Medellín (Tesis de maestría, Universidad de Antioquia). Repositorio Institucional UdeA. http://bibliotecadigital.udea.edu.co/dspace/ bitstream/10495/1391/1/tesis.pdf

Vásquez, M., \& Carrasco, A. (2017). Género, cuerpo y heteronormatividad. Reflexiones desde la antropología. Interciencia, 42(9), 616-622. https:/www.interciencia.net/wp-content/ uploads/2017/10/10-616-42-9.pdf 